\title{
EL AUGE ECONÓMICO DE CARTAGENA Y LA REVITALIZACIÓN DEL SURESTE ESPAÑOL EN LOS SIGLOS XVI Y XVII
}

\author{
por \\ FRANCISCO VELASCO HERNÁNDEZ \\ Universidad de Murcia*
}

RESUMEN: Con la llegada del siglo XVI se inicia una nueva etapa de prosperidad en Cartagena y Alicante, apoyada en la intensa actividad mercantil generada por sus puertos. Este esplendor económico sirvió para revitalizar un espacio basta entonces adormecido: el Sureste español. Tomando como referencia el puerto de Cartagena, bemos analizado la enorme dimensión de sus relaciones comerciales, las mercancías traficadas, su producción y comercialización, la actuación de su burguesía mercantil y los efectos de una fiscalidad desmesurada que estimuló el contrabando y que fue responsable en última instancia del estancamiento posterior cartagenero. Sobre la base de una intensa labor de documentación en archivos españoles, como los municipales de Cartagena y Murcia, Histórico Provincial de Murcia, de la Real Chancillería de Granada, Histórico Nacional o Archivo General de Simancas, y de otros extranjeros, como el Archivio di Stato de Génova o los Archives Nationales de Francia, bemos tratado de rellenar una laguna bistoriográfica que se mantiene basta boy día y que impide que se valore adecuadamente este importante ámbito económico de la España de los Austrias.

Palabras Clave: Cartagena. Alicante. Comercio internacional. Actividad portuaria. Sureste español. Mediterráneo occidental.

ABSTRACT: With the arrival of the sixteenth century, a new stage of prosperity begins in Cartagena and Alicante, supported by the intense mercantile activity generated by its ports. This economic energy served to revitalise a previously dormant space: the Spanish southeast. Taking as a starting point the harbour of Cartagena, this article analyses the enormous magnitude of commercial relationships, the goods exchanged, their production and commercialisation, the behaviour of the mercantile bourgeoisie and the effects of exorbitant taxation that stimulated smuggling and

* Seminario Familia y Elite de Poder en el Reino de Murcia, siglos XV-XIX. 
was ultimately responsible for the later stagnation of Cartagena. Through extensive archival work at the municipal archives of Cartagena and Murcia, the Archivo Historico Provincial (Murcia), the Real Chancilleria (Granada), the Archivo Histórico Nacional (Madrid), the Archivo General (Simancas), the Archivio di Stato (Génova), and the Archives Nationales (Paris), the article attempts to fill a bistorical lacuna. This lacuna has bitherto prevented a full appreciation of the economic environment of Habsburg Spain.

KEY WORDS: Cartagena. Alicante. International trade. Ports. Western Mediterranean.

\section{INTRODUCCIÓN}

Muchas hipótesis se han vertido sobre la decadencia de Cartagena y del Sureste español tras la Edad Antigua. Quizá la vieja tesis de Pirenne sobre la recesión de un Mar Mediterráneo de ciudades vertebradas en torno a Roma y apoyadas en una intensa actividad mercantil entre ellas, en contraposición a un mundo medieval ruralizado, podría servir como fórmula explicativa de la larga postración de núcleos portuarios, como Cartagena o Alicante, que no resurgen hasta comienzos del siglo XVI, en base a nuevas perspectivas de tipo político, económico y militar.

En este sentido, los últimos tiempos medievales se caracterizaron por la búsqueda de nuevos mercados en un Mediterráneo occidental que adquiría cada vez más protagonismo en el mapa económico europeo. En una afirmación muy acertada, el historiador italiano F. Melis señalaba como por esos años el Mediterráneo comenzaba a fragmentarse en dos áreas con actividades dominantes, polarizadas en dos tipos de productos: el «área de las especias», en la cuenca oriental, de actividades especulativas y productos caros; y el «área de la lana», en la cuenca occidental, donde prevalecía el comercio de ésta y otras materias primas relacionadas con la alimentación (como los cereales, las pasas, el vino o el aceite) y la industria textil (caso del alumbre). Será precisamente en esta última área donde van a progresar ciudades como Alicante y Cartagena, puertos terminales de la lana castellana, continuando - en parte - la labor anteriormente desarrollada por Barcelona y Valencia. Además, la prosperidad de la revitalizada «vía del Estrecho» (tras el descubrimiento de América) y de la ruta que comunicaba el Atlántico con el Mediterráneo acabó favoreciendo a los puertos mejor situados en torno a ese tráfico, esto es, Málaga, Cartagena y Alicante, creando nuevos mercados y nuevas posibilidades de negocio más allá de la viejas metrópolis italianas, flamencas o francesas.

El siglo XVI constituye, por tanto, el punto de arranque de un nuevo período de prosperidad para Cartagena y Alicante en el que ha de jugar un papel decisivo la actividad mercantil desplegada desde sus puertos. Ese largo siglo XVI (en expresión braudeliana) produjo un crecimiento generalizado en Europa, apoyado en gran medida sobre el comercio. De hecho, este aumento sensible de los intercam-

Hispania, LXV/2, núm. 220 (2005) 485-514 
bios comenzó a convertir el mercado europeo en mercado mundial y a gestarse lo que I. Wallerstein denominó economía-mundo europea ${ }^{1}$. Sin embargo, en lo que respecta a la actividad mercantil del Sureste español en las primeras fases de la Modernidad hemos de señalar su total desconocimiento en la historiografía española, a pesar de que se intuía su participación en las líneas maestras del tráfico internacional de la época. Parecía como si el brillo del comercio andaluz, representado por el conjunto Sevilla-Cádiz-Málaga hubieran eclipsado, una vez confirmada la crisis medieval de Barcelona y Valencia, cualquier otra posibilidad mercantil en el litoral mediterráneo español.

Sin embargo, el análisis de la documentación consular italiana (F. Braudel, R. Romano, E. Grendi), inglesa (H. Kamen) y francesa (G. Lemeunier) relacionada con Alicante y Cartagena confirmó la existencia de otros enclaves portuarios relevantes lejos del núcleo andaluz, como las propias ciudades mencionadas, o lo que es lo mismo, en el espacio litoral del Sureste, el área más importante de lo que Braudel denominó la Mancha mediterránea.

A grandes rasgos, la trayectoria cartagenera y alicantina va a ser muy similar en sus primeras fases, y en ambos casos nos produce una sensación de asombro al comprobar el rápido desarrollo alcanzado por estos pequeños pueblos pesqueros medievales que son capaces de rivalizar a comienzos del siglo XVII con las principales plazas comerciales españolas del momento, tal como podrá apreciarse, y en una evolución tan sólo comparable a la desplegada por Cádiz o Málaga.

En el caso principal que nos ocupa, Cartagena, la llegada del siglo XVI abre una nueva y brillante página en su historia. Definitivamente se pone fin al prolongado letargo medieval y se sientan las bases de la futura expansión económica: el crecimiento es constante a lo largo de toda esta centuria, la población se multiplica casi por diez (tendencia sólo apreciable en otros puertos como Sevilla, Cádiz, Málaga o Alicante), el perímetro urbano se ensancha notablemente y comienza a ser efectiva la colonización del campo cartagenero, se ponen en cultivo nuevas tierras y una nueva agricultura orientada hacia el mercado, se mejoran y amplían los muelles, al tiempo que se organizan experiencias preindustriales, y las relaciones comerciales con otros pueblos no dejan de incrementarse. Es una imagen de prosperidad que se prolongará durante más de un siglo y a la que sólo pondrá freno el momento más duro de la crisis del siglo XVII, coincidente en nuestro caso con los años centrales de esa centuria ${ }^{2}$.

1 WALLERSTEIN, I.: El moderno sistema mundial, 2 vols., Madrid, 1979-1984.

2 El desarrollo económico de Cartagena en los siglos XVI y XVII ha sido abordado en VeLASCO HERNÁNDEZ, F.: Auge y estancamiento de un enclave mercantil en la periferia: El nuevo resurgir de Cartagena entre 1540 y 1676, Murcia, 2001, y para un espacio de tiempo más limitado en VeLASCO Hernández, F.: Comercio y actividad portuaria en Cartagena (1570-1620), Cartagena, 1989, a cuyas páginas nos remitimos para una mayor amplitud de detalles. Para una visión más general de la Cartagena de los Austrias: MONTOjo MONTOjo, V: El siglo de Oro en Cartagena (1480-1640), Murcia, 1993; y TORnel CoBACHO, C.: El gobierno de Cartagena en el Antiguo Régimen, Cartagena, 2001. 
Pero el balance es positivo, a pesar de las terribles epidemias de peste de 1648 y 1676. De hecho, Cartagena rebasará con creces los 10.000 habitantes a fines del siglo XVII, más del doble de la población estimada al acabar la centuria anterior. Es un comportamiento muy diferente al de la mayor parte de las ciudades castellanas, tanto por el momento de incorporación a la crisis, como por su respuesta ante la misma. Pero aún más sorprendente es el hecho de que sea precisamente en ese siglo XVI, y en medio de un ambiente general de crisis 'económica, claramente perceptible en Castilla y en gran parte de Europa, cuando comienza el despegue de Cartagena, en una fase de crecimiento continuo que la ha de convertir por algunas décadas en un emporio comercial de gran relieve, en directa competencia con el vecino puerto de Alicante, el otro gran enclave del Sureste.

\section{LA REVITALIZACIÓN DEL SURESTE ESPAÑOL Y LA IMPORTANCIA DE LA MANCHA MEDITERRÁNEA}

Desde los últimos tiempos medievales comienza a reivindicarse con fuerza un espacio marítimo hasta entonces adormecido: el Sureste español. En este sentido, la reactivación económica del Mediterráneo occidental, capitaneada por Génova, Marsella y Valencia, la reorientación de la política exterior de los Reyes Católicos hacia Italia y norte de África y la concentración del tráfico con América en los puertos meridionales de Castilla constituyó un poderoso revulsivo para el avance de la Mancha mediterránea, un ámbito geográfico que se iniciaba en el Estrecho de Gibraltar y finalizaba en los puertos de Denia (España) y Argel (Magreb).

Dentro de él, el Sureste hispánico constituía una especie de punta de lanza, cuyo valor estratégico se magnificaba por la excelente comunicación con la capital del Imperio hispánico (Toledo y después Madrid) y su ubicación en las rutas que enlazaban con Italia, Francia y los Presidios norteafricanos. Esta situación de encrucijada revalorizó su papel político, económico y militar a lo largo del Quinientos, de tal forma que cuando se anuncien los primeros síntomas de crisis en Castilla, el interior peninsular, otrora expansivo, va a ceder protagonismo a una periferia que comienza a crecer de forma acelerada. La decadencia comercial de algunas de las áreas tradicionales, como las ferias castellanas (en declive desde 1560) o el arco cantábrico (muy afectado por el inicio de las guerras con ingleses y holandeses), tendrá importantes compensaciones en el Mediterráneo peninsular con el surgimiento de lo que Vázquez de Prada denominó «nuevos puertos españoles», esto es, Málaga, Cartagena y Alicante,

3 VÁZQUEZ DE PRADA, V.: «La actividad económica del Levante español en relación con Italia a finales del siglo XVI", en VI Congreso de Historia de la Corona de Aragón, Madrid, 1959, p. 902. El resurgimiento económico de estos puertos en el siglo XVI ha sido abordado también en: SALVADOR

Hispania, LXV/2, núm. 220 (2005) 485-514 
los cuales ofrecen desde mediados del siglo XVI unos comportamientos mercantiles muy dinámicos, atrayendo hacia sí un importante flujo comercial y el interés de la burguesía mercantil europea.

A pesar de que Cartagena y su hinterland configuran nuestro campo espacial de actuación, no es difícil apreciar la multitud de interrelaciones existentes entre los dominios litorales del Sureste español. Mazarrón, por ejemplo, quedó estrechamente unido al puerto cartagenero desde su surgimiento a fines del siglo XV. Lo que en un principio pudo ser una tímida competencia por en el embarque masivo de alumbres desde un pequeño muelle próximo (el futuro Puerto de Mazarrón), no tardó en ser aprovechado como otra posibilidad más de negocio por aquellos mercaderes genoveses que trasladaban la lana del interior castellano hacia Cartagena, vía Italia, de tal manera que con el tiempo el Puerto de Mazarrón quedó como una rada auxiliar de la cartagenera, facilitada por su proximidad a ésta (unos $30 \mathrm{Kms}$.). La cercanía provocó asimismo la dependencia casi total de esta pequeña villa con respecto a la burguesía cartagenera, la cual controlaba su abastecimiento, la explotación de sus minas, sus rentas, etc.

Esa burguesía mercantil, que nunca creyó en los límites administrativos, extendió su círculo económico y financiero al control de las producciones de otros espacios marítimos próximos, como la sal de Torrevieja y La Mata (Alicante) o la barrilla, esparto o alumbre del territorio almeriense. Pero nada de esto era comparable a la rentabilidad que obtenían con la combinación de las funciones portuarias de Alicante y Cartagena (fletes más baratos, reducción de costes en el transporte por tierra, fácil salida de la producción interior). Dicha situación se refrendaba periódicamente en los contratos de flete o seguro firmados en Cartagena, en cuyas cláusulas siempre se obligaba al patrón de la nave a hacer escala en Alicante (exclusivamente), al objeto de completar su carga de sosa, barrilla o lana ${ }^{4}$. De hecho, los mercaderes genoveses, marselleses o bretones vivían a caballo entre estos dos puertos, jugando en su beneficio con las condiciones fiscales de uno y otro. De ahí que se repitieran con frecuencia las peticiones de vecindad, los desavecindamientos y las investigaciones para desenmascarar los falsos empadronamientos de unos y otross.

ESTEBAN, E: «España y el comercio mediterráneo en la Edad Moderna», en El comercio en el Antiguo Régimen, vol. II (1995), pp. 18-40.

4 Hemos analizado cerca de 300 escrituras de fletamento de naves, muchas de ellas especificadas con sus cláusulas respectivas en una relación de más de 150 fletes contratados en el puerto de Cartagena entre 1577 y 1673, y que publicamos en: Auge y estancamiento de un enclave mercantil..., pp. 96-99. Las fuentes utilizadas han sido exclusivamente protocolos notariales de Cartagena, custodiados en el Archivo Histórico Provincial de Murcia (A.H.P.M.), desde el protocolo n 5159 (año 1577), fol. 264, al protocolo 5443 (año 1673), fol. 46.

5 Veamos un ejemplo al respecto: en 5 de enero de 1572 se decidió desavecindar, aunque con la oposición de los regidores Alonso Ardid y Nicolás Rosique, a los mercaderes genoveses Alejandro Imperial y Gerónimo Scipión ya que «los susodichos habrá ocho meses que no están ni residen en esta ciudad, por que el dicho Gerónimo Scipión reside en la ciudad de Alicante y el dicho Alejandro 
En la evolución comercial del Mediterráneo español en la época de los Austrias, Alicante constituye un caso de especial interés, en parte porque su devenir es muy similar al cartagenero, sirviéndonos como punto de referencia válido para medir ambos comportamientos. Desde que en 1490 adquiere la categoría de ciudad, Alicante no deja de crecer. Diversos factores le van a beneficiar con respecto a Valencia: la crisis valenciana relacionada con las germanías, el asentamiento paulatino de mercaderes genoveses, apuntado por el cronista Vicia$\mathrm{na}^{6}$, la reducción a la mitad de los derechos aduaneros con Castilla desde 1550 , que afectaron fundamentalmente al tráfico lanero ${ }^{7}$, y sobre todo, su mejor situación en torno a las rutas que unían a los puertos italianos con los atlánticos. El resultado inmediato se ha de ver en una expansión comercial prolongada que, como en el caso cartagenero, rebasará con creces el primer tercio del siglo XVII. Pero al igual que nuestro puerto, su modelo de crecimiento se apoyará en la exportación de determinados productos locales y foráneos destinados a la industria europea (como la lana, barrilla, sosa, esparto o jabón), en la redistribución de productos importados hacia el interior castellano y en el asentamiento de poderosas colonias mercantiles, en su mayoría de procedencia extranjera (franceses, genoveses, ingleses, etc.). Realmente, Alicante formaba con Cartagena un poderoso espacio económico, una especie de circuito mercantil a dos bandas, aunque con cierta participación de otros puertos menores, como Mazarrón, Torrevieja, Santa Pola o Denia, que quedaba plenamente integrado en la ruta que unía el Mediterráneo con el Atlántico; de ahí que sus trayectorias fueran similares. Sin embargo, a diferencia de Cartagena, Alicante conoció una rápida recuperación a partir de 1650 , en la que tuvo mucho que ver el diferente tratamiento fiscal de ambas. Este nuevo empuje tras la crisis la convertirá, tal como señala Kamen, en el principal puerto español en la época de Carlos II después del complejo Sevilla-Cádiz ${ }^{8}$.

En realidad, el binomio Cartagena-Alicante está aún por estudiar, al igual que el progresivo basculamiento político y económico de la España de los Austrias hacia este ámbito litoral, tan íntimamente conectado con las posesiones africanas e italianas. La importancia de ambos puertos, especialmente estratégicos para la Monarquía hispánica, no ha sido calibrada en su justa medida, en parte debido a la dispersión documental, pero también por su pertenencia a espacios jurisdiccionales diferentes. De hecho, la partición del Sureste español en diferentes fronteras político-administrativas lo diluyó como espacio homo-

\footnotetext{
Imperial en la de Génova y no están, ni residen aquí, ni contribuyen con los pechos y derechos que son obligados» (A.M.C. Ac. cap. 5-I-1572).

6 Cit. por GIMÉNEZ LÓPEZ, E.: Alicante en el siglo XVIII. Economía de una ciudad portuaria en el Antiguo Régimen, Valencia, 1981, pp. 64-65.

7 CASEY, J.: El Reino de Valencia en el siglo XVII, Madrid, 1983, pp. 83-84.

8 KAMEN, H.: La España de Carlos II, Barcelona, 1981,.p. 186. Este progreso alicantino ha sido también constatado por DUEÑAS MOYA, M.C.: Territorio y jurisdicción en Alicante: el término general durante la Edad Moderna, Alicante, 1997.
} 
géneo a lo largo de los siglos, a pesar de que conformaba una unidad natural bien definida, tanto desde el punto de vista físico (aridez, falta de lluvias, altas temperaturas, escasez de cursos fluviales, vegetación pobre y adaptada) como humano (grandes vacíos demográficos, población muy concentrada en pocos núcleos, territorios fronterizos y marginales). Por tanto, creemos que es necesario recuperar historiográficamente este espacio geográfico dividido de forma artificial, cuyas fronteras administrativas fueron soslayadas entonces por la actividad mercantil del capitalismo europeo aprovechando la oferta productiva similar de ambas ciudades y comarcas (barrilla, sosa, esparto, alumbres, sal, jabón, bizcocho) y la salida por sus puertos de producciones exógenas (lana, seda, paños, trigo, etc.).

Alicante fue, sin lugar a dudas, el gran competidor de la rada cartagenera durante la Modernidad, incluso pudo estar más vinculado a Cartagena que a Valencia. La relación entre ambos puertos constituyó una difícil combinación entre rivalidad y complementariedad, a la que no fueron ajenas sus múltiples similitudes. Ambas presentaban características análogas: cifras de población muy cercanas (Cartagena osciló entre los 1.034 vecinos de 1591 y los 1.441 de 1626, en tanto Alicante rondó entre los 1.262 vecinos de 1602 y los 1.276 de 1629), salvo en el período más álgido de la crisis del XVII (Cartagena se movió entre los 866 vecinos de 1638 y los 765 de 1663 , mientras que Alicante se mantuvo en torno a los 1.156 de 1645 y los 1.439 de 1660$)^{9}$; pero también compartían otra serie de afinidades de carácter físico, humano o económico. De ahí que el factor complementariedad jugase un papel muy importante en el devenir de ambas ciudades, sobre todo en los momentos de expansión económica (no así en los años más duros de la crisis, lo que exacerbó la rivalidad secular).

Por consiguiente, hemos insistido en un entorno económico más amplio, el Sureste español, cuya oferta similar era aprovechada por el capitalismo mercantil para conseguir fletes más baratos. Sencillamente ese es el motivo fundamental por el que Alicante figuraba como puerto de origen de las embarcaciones llegadas - y no Cartagena - a las principales radas italianas (Génova, Livorno, Venecia), esto es, el último punto tocado $-\mathrm{y}$ por tanto el que se registraba en la contabilidad portuaria - por los barcos fletados en el Sureste, lo cual ha llevado en ocasiones a fáciles juicios de valor sobre la desorbitada importancia de Alicante en relación a Cartagena ${ }^{10}$. Otra cosa bien distinta es la fuerte rivalidad que llegó a suscitarse

9 AlBerola ROMÁ, A.: Jurisdicción y propiedad de la tierra en Alicante. Siglos XVII y XVIII, Alicante, 1984, pp. 65-69, y TORRES SÁNCHEZ, R.: Ciudad y población. El desarrollo demográfico de Cartagena durante la Edad Moderna, Cartagena, 1998, pp. 38-44. Las cifras de Cartagena de 1591 corresponden al vecindario de 1591 (A.G.S., Tesoro, Inv. 24, leg $^{\circ} 1.301$ ); las de 1626 al padrón de moneda forera de ese año (A.M.C., Caja 12, exp. 5), al igual que los padrones de moneda forera de 1638 (A.M.C. Caja 32, exp. 9) y 1663 ((A.M.C. Caja 32, exp. 1).

10 Grendi, E.: La repubblica aristocratica dei genovesi. Politica, carità e commercio fra Cinque e Seicento, Bolonia, 1987, pp. 342 y ss.; BRAUDEL, F/ROMANO, R.: Navires et marchandises à la entrée du port de Livourne, 1547-1611, Paris, 1951, pp. 35-46; GUARNIER, G.: Livorno Medicea nell quadro della sua atrezature portuali e della funzione economica-maritima (1537-1737), Livorno, 1970, pp. 3341; y ZORZI, A.: La vita quotidiana a Venezia nel secolo di Tiziano, Milano, 1997. 
entre ambas debido a la gran diferencia fiscal existente, que benefició sobremanera a Alicante en detrimento de la Cartagena castellana.

La posición interior de la ciudad de Murcia no impedía su integración en el circuito económico del Sureste. Perfectamente comunicada con Alicante y Cartagena (a 80 y 50 kilómetros de ambas), constituía uno de los vértices del triángulo mercantil surestino, aportando otras potencialidades interesantes a ese circuito: un importante centro de consumo, capital del reino y sede del obispado, una agricultura rica y próspera, además de un gran valor añadido: el cultivo y comercialización de la seda, que llegó a convertirse en su activo más importante y en uno de los principales artículos de exportación del Sureste ${ }^{11}$. A pesar de no ser una ciudad portuaria, su modelo socioeconómico acabó totalmente orientado hacia el exterior, en un proceso de clara extroversión económica ${ }^{12}$.

Aunque quedaba fuera del Sureste español, la vinculación con respecto a las metrópolis levantinas, su relación con las plazas africanas y con el entorno indiano, así como su trayectoria similar, hacen de Málaga otro de los elementos destacados de la Mancha mediterránea. Si bien su desarrollo portuario no tenía nada de «nuevo» - parafraseando a Vázquez de Prada-, pues su primacía mercantil en el reino granadino se mantuvo a lo largo de la Baja Edad Media ${ }^{13}$, la rada malagueña va a conocer en los siglos XVI y XVII, con Cartagena y Alicante, un período de prosperidad incuestionable, que arranca con el establecimiento de Presidios en el Magreb y con algunos intentos de participación en el comercio americano. Su vocación sedera, forjada durante la etapa nazarita, junto al comercio de pasas y vinos dulces, constituyó uno de los nervios fundamentales de su expansión comercial a lo largo del siglo XVI, la cual no pudo interrumpir la revuelta morisca de 1568 , en parte por el relanzamiento de su puerto desde 1580, tras las obras de ampliación y mejora de sus muelles ${ }^{14}$. Además, su oferta exportadora se enriqueció con la atracción de diversas pro-

11 Chacon, F.: Murcia en la centuria del Quinientos, Murcia, 1979, pp. 339-370, y MiRAlles MARTínEZ, P.: La sociedad de la seda. Comercio, manufactura y relaciones sociales en Murcia durante el siglo XVII, Murcia, 2002.

12 Perez Picazo, M.T./Lemeunier, G.: El proceso de modernización de la Región Murciana (Siglos $X V I-X I X)$, Murcia, 1984, pp. 76 y ss.

13 El sistema económico malagueño y el comercio generado por su puerto en los últimas décadas medievales ha sido estudiado fundamentalmente por: LÓPEZ BELTRAN, M.T.: El puerto de Málaga en la transición a los tiempos modernos, Málaga, 1986, y de la misma autora: «Corso y piratería en el comercio exterior del reino de Granada en época de los Reyes Católicos» en Baetica, $\mathrm{n}^{\circ} 22$ (2000), pp. 373-389, «Financiación de los viajes y cobertura de los riesgos en el trafico marítimo malagueño en época de los Reyes Católicos. I: cambios y prestamos marítimos", Baetica, nº 19 (1997), pp. 51 65 y «II: seguros marítimos», Baetica, $\mathrm{n}^{\circ} 21$ (1999), pp. 281-300. También se ha ocupado de ello: LÓPEZ DE COCA CASTAÑER, José Enrique: «Sobre las galeras venecianas de poniente y sus escalas ibéricas (siglo XV)», Cuadernos de Estudios Medievales y Ciencias y Técnicas Historiográficas, $\mathrm{n}^{\circ}$ 21-23 (1995-1998), pp. 401-416, y «Los genoveses en Málaga durante el reinado de los Reyes Católicos», en Anuario de Estudios Medievales, $\mathrm{n}^{\circ} 10$ (1980), pp. 619-650.

14 Rodríguez Alemán, I.: El puerto de Málaga bajo los Austrias, Málaga, 1984 pp. 122 y ss.

Hispania, LXV/2, núm. $220^{\circ}(2005)$ 485-514 
ducciones exógenas, como la lana, el azúcar y el aceite, que otorgaban un mayor vigor a su comercio. Por ello, la línea evolutiva del comercio malagueño se mantuvo firme a lo largo de la primera mitad del siglo XVII, como ocurrió en Alicante y Cartagena. Sólo a partir de 1660-1670 las rentas municipales relacionadas con el comercio comienzan a caer de forma brusca, representando tan sólo dos décadas después el $50 \%$ de su valor anterior ${ }^{15}$.

$\mathrm{Al}$ otro lado de la Mancha mediterránea, los países del Islam representaban un papel secundario en el comercio, aunque no por eso desdeñable. Ejercían una doble actividad, en la que el ejercicio de la piratería se combinaba con un comercio alternativo con países como Francia o las repúblicas italianas. Sin embargo, para los intereses españoles e incluso para el tráfico marítimo regular constituían una autentica pesadilla, que se magnificaba con la cercanía de Argel, el gran nido de corsarios de la época ${ }^{16}$. Pero no todo era negativo, pues la existencia de los presidios españoles del norte de África hacían de vasos comunicantes con las modestas economías magrebíes, fomentada por la intermediación de los judíos afincados en Orán, Mazalquivir o Ceuta, muchos de ellos descendientes de los expulsados en 1492. La conquista de estas plazas africanas, iniciada en el reinado de los Reyes Católicos, promovió la apertura de nuevas vías de intercambio en mercados donde la presencia castellana era en la práctica casi nula, las cuales no tardarían en ser aprovechadas por los mercaderes cartageneros y alicantinos. Con el tiempo hubo también un reparto de influencias territoriales, en el que Melilla, Ceuta, Tánger y Peñón de Vélez cayeron bajo la órbita de Málaga y Cádiz, mientras que Orán y Mazalquivir bascularon hacia Cartagena, constituyendo uno de los principales activos de su comercio, del que también sabrá aprovecharse Alicante ${ }^{17}$.

15 Esta crisis finisecular del comercio malagueño estaría motivada por la coyuntura política internacional de la segunda mitad del siglo XVII, las epidemias de peste (sobre todo la de 1678-80), el terremoto de 1680 y la brutal deflación de ese mismo año (QUINTANA TORET, F.J.: «La crisis del comercio malagueño en la transición del siglo XVII al XVIII (1678-1714)», en Baetica, $\mathrm{n}^{\circ}$ 7, pp. 280-286. También ha versado sobre ello en: «El comercio malagueño en el siglo XVII», en Pedralbes. Revista d'Història Moderna, $\mathrm{n}^{\circ} 7$ (1987), pp. 79-102; «Organización y crisis de la hacienda municipal malagueña en el siglo XVII (1665-1700)», Jábega, no 48 (1984), pp. 15-22 y «La coyuntura económica en la Andalucía Oriental: Málaga, 1650-1750, en La burguesía de negocios en la Andalucía de la Ilustración, Cádiz, 1991, t. I, pp. 147-164).

16 FONTENAY, M.: «Los fenómenos corsarios en las periferización del Mediterráneo en el siglo XVII", en Seminario sobre periferización del Mediterráneo Occidental (Siglos XII-XVIII), Murcia, 1986, p. 119 y «La Maghreb barbaresque et l'esclavage méditerranéen aux XVIe-XVIIe siècles», en Les Cabiers de Tunisie, t. XLIV, $\mathrm{n}^{\circ}$ 157-158 (1991), pp. 7-43. También BELHAMISSI, M.: Les captifs algériens et l'Europe chrétienne (1516-1830), Argel, 1988.

17 Sobre este tema véase: ALONSO ACERO, B.: Orán-Mazalquivir, 1589-1639: una sociedad española en la frontera de Berbería, Madrid, 2000; SÁNCHEZ DONCEL, G.: Presencia de España en Orán, Toledo, 1991; VILAR, J.B./LOURIDO, R.: Relaciones entre España y el Magreb. Siglos XVII y XVIII, Madrid, 1994 y Gutierrez CruZ, R: Los presidios españoles del norte de Africa en tiempos de los Reyes Católicos, Melilla, 1997.

Hispania, LXV/2, núm. 220 (2005) 485-514 
Contamos, en definitiva, con un espacio económico nuevo, que surge con enorme fuerza, y que acapara importantes parcelas de protagonismo en el devenir de la España de los Austrias. Un ámbito al que, sin embargo, la historiografía española ha prestado escasa atención (ocupada en la crisis de las ferias castellanas y de los puertos cantábricos, en la apertura atlántica, etc.), pero que reclama un estudio adecuado que lo sitúe en la posición histórica que merece. Empero, nos centramos aquí en el caso de Cartagena.

\section{EL AVANCE CARTAGENERO: LAS FASES DE UN CRECIMIENTO ESPECTACULAR}

En verdad, el proceso de conversión de esta pequeña localidad portuaria medieval, de fuerte base agropecuaria, en un importante emporio comercial con fuertes implicaciones en otros centros económicos europeos, no va a ser fácil, y, ni mucho menos, improvisado. Hubo un crecimiento lento anterior, que comienza a concretarse a finales del siglo XV al amparo de una nueva coyuntura política (incorporación del marquesado de Villena, alejamiento de la frontera granadina, inicio de las expediciones a Italia y Berbería) y económica (salida de la lana manchega y murciana, a la que se suma ahora la granadina, descubrimiento de los alumbres de Mazarrón, exportación por vía marítima de tejidos toledanos y segovianos, etc.), de tal forma que el camino de Toledo a Cartagena acaba consolidándose como una ruta fundamental en el comercio castellano.

Existían, por tanto, unos claros precedentes que confirmaban la existencia de un tráfico hacia y desde Cartagena más o menos intenso. En este sentido, ha sido suficientemente documentada la salida de buena parte de la lana andaluza, manchega o murciana por el puerto de Cartagena desde el siglo XV, al igual que la llegada de buen número de carreteros de estas zonas a la búsqueda de pescado, sal o alumbre locales y de manufacturas y productos exóticos procedentes del exterior ${ }^{18}$. Este continuo flujo de hombres y mercancías queda reflejado en la creación de nuevos impuestos sobre el tráfico marítimo a fines del

18 CASADO AlONSO, H.: "Comercio internacional y seguros marítimos en Burgos en la época de los Reyes Católicos», en Congreso Internacional Bartolomeu Dias e a sua época, vol. III, Oporto, 1989, pp. 585-608; MOLENAT, J.P.: «Les communications en Nouvelle Castille au XVe siècle et au début du XVIe siècle», en Les comunications dans la Péninsule Ibérique au Moyen Age, París, 1980, pp. 155162; Menjot, D./CECCHI, E.: «Murcie dans le grand commerce international à l'orée du XVe siècle, d'après les archives Datini», en Miscelánea Medieval Murciana, vol. XV (Murcia, 1989), pp. 121-137; RODRíGUEZ LlOPIS, M.: «La integración del Reino de Murcia en el comercio europeo al fin de la Edad Media», en Castilla y Europa. Comercio y mercaderes en los siglos XIV, XV y XVI, Burgos, 1995, pp. 91-96; GUIRAL-HADZIIOSSIF, J.: Valencia, puerto mediterráneo en el siglo XV (1410-1525), Valencia, 1989, pp. 398-422; Franco Silva, A.: El alumbre del Reino de Murcia, Murcia, 1996, pp. 263-315; y MonTojo MonTOJO, V.: «Mercaderes y actividad comercial a través del puerto de Cartagena en los reinados de los Reyes Católicos y Carlos V (1474-1555)», en Miscelánea Medieval Murciana, $\mathrm{n}^{\circ} 18$ (1993-1994), pp. 109-140.

Hispania, LXV/2, núm. 220 (2005) 485-514 
siglo XV, como el anclaje de navíos o el mollaje - sobre la utilización del muelle-, lo que demuestra una cierta expansión portuaria ${ }^{19}$.

Esta primera fase de crecimiento lento se cierra hacia 1540-1550. Es posible que durante esa primera etapa la supervivencia del emporio mercantil valenciano, el surgimiento de la rival Alicante, la fortaleza del sistema de Amberes - hacia el que basculaba buena parte de la economía castellana- o la «revolución» del comercio colonial, concentrado en los puertos andaluces, impidieran una evolución más explosiva del sector terciario cartagenero. Sin embargo, a partir de esa década y hasta 1648, aproximadamente, se inicia una nueva fase, enormemente expansiva, que podríamos denominar el «siglo de oro del comercio cartagenero». Este comportamiento positivo del sector mercantil se aprecia también en la trayectoria de otros puertos cercanos como Alicante (consigue rebajar a la mitad los derechos aduaneros con Castilla), Málaga (inicia la construcción de un gran puerto comercial) y Valencia (aprovechando el tirón de las importaciones), aunque no así en Almería. Es posible que en el caso cartagenero -e incluso en el malagueño- la función militar precediera a la mercantil, complementándola de alguna forma. Sobre todo teniendo en cuenta el gran despliegue político de la Corona española en el Mediterráneo (campañas de Nápoles, Mazalquivir, Orán, Túnez, Argel, Bugía o Lepanto), que entre otras cosas facilitó la instalación de la «Casa del Rey» o atarazanas reales, la Proveeduría de Armadas, la invernada de las Galeras y el abastecimiento de las plazas norteafricanas. De hecho, la ubicación de la Proveeduría fomentó el comercio con Orán, la creación de flujos de aprovisionamiento desde el interior o por vía marítima y la firma de numerosos «asientos» con la Corona por la burguesía mercantil de Cartagena. Constituía en ese sentido un incentivo más para las actividades mercantiles, como bien acreditan los numerosos fletes contratados por aquella.

Pero el empujón definitivo le vino a Cartagena - como a su vecina Alicante- del exterior. $Y$ en este punto es necesario otorgarle gran parte del protagonismo a la República de Génova y a sus mercaderes. Con bastante anterioridad a 1492, los genoveses habían acaparado importantes parcelas de poder económico en Castilla, y la expulsión de los judíos ese mismo año no vino sino a confirmar un predominio financiero y comercial que se reforzará en las siguientes centurias. En el reino de Murcia, como en muchos otros territorios castellanos, los negocios de judíos fueron transferidos a los mercaderes italianos, ampliando su nivel de penetración en las estructuras económicas regionales. Desde entonces su presencia en el antiguo reino murciano y en su principal puerto (Cartagena) se convierte en una constante secular, potenciada con la explotación de nuevos recursos como el alumbre, la lana, la barrilla o el jabón, que venían a completar su tradicional «saca de moneda castellana» de oro y plata ${ }^{20}$.

19 A.G.S., Registro General del Sello, 18-IX-1503 y A. M. C. Caja 107, exp. 3.

20 La inmigración genovesa en Cartagena durante los siglos XVI y XVI, así como la actuación de su burguesía mercantil, han sido estudiadas por: TORRES SANCHEZ, R.: «La colonia genovesa en 
Pero, ¿por qué Cartagena?, y no otros enclaves portuarios más o menos próximos de la Mancha mediterránea, como, Almería, Mazarrón, Santa Pola o Denia (obviamos lógicamente a Alicante). En realidad, existen un buen número de razones que nos pueden ayudar a encontrar una o varias respuestas adecuadas. Cartagena contaba, en primer lugar, con excepcionales cualidades físicas, tales como un extraordinario puerto-refugio, el profundo calado de sus aguas, muelles naturales, etc., a las que se unían otras de carácter político, como la instalación de la «Casa del Rey» y la Proveeduría de Armadas, el apoyo militar de la Monarquía desde las expediciones de Orán y Mazalquivir o su carácter de fondeadero temporal de las Galeras del rey. Debemos añadir también las fiscales, tales como la exención del almojarifazgo, las aduanas de puertos secos o la franquicia de alcabala y moneda forera. Y como no, las estratégicas, esto es, buena situación frente a las principales rutas de comercio, una parada técnica casi obligada para el aprovisionamiento de tropas y armadas, etc, etc. A todo ello habría que sumar la situación política favorable del último tercio del siglo XVI, cuando las prolongadas guerras con ingleses, holandeses y franceses arruinaron el tradicional comercio castellano del Atlántico norte, desviándolo en parte hacia las repúblicas italianas, cuyos mercaderes acaparaban y redistribuían en buena parte de Europa.

Estos hechos y otros muchos factores favorables permitirán a partir de 1540 1550 el establecimiento permanente de colonias mercantiles, cuya actividad será en gran parte responsable del desarrollo comercial de la ciudad, en un proceso expansivo que sólo a partir de 1635 experimentará un cambio de tendencia significativo y al que la epidemia de 1648 situará en sus cuotas más regresivas. La tímida recuperación posterior no será suficiente para retornar a valores anteriores, prolongando una fase anodina que tocará fin con la peste de 1676, a partir de la cual otras expectativas y posibilidades prepararán una nueva etapa histórica para la ciudad.

\section{UNAS RELACIONES COMERCIALES DE CARÁCTER UNIVERSAL}

Obviamente, las consecuencias de la intensa labor desplegada por los mercaderes afincados en Cartagena no tardarán en apreciarse: el volumen de intercambios creció de manera espectacular, así como la circulación de dinero, contratación de seguros, operaciones de crédito, etc. Con relativa facilidad y en breve espacio de tiempo, pasaron a dominar una gran parte de los sectores productivos de la comarca, desplazando en cierto modo a la pequeña burguesía

Cartagena durante la Edad Moderna», en Congreso Internacional «Rapporti Genova-MediterraneoAtlantico nell'età moderna». Génova, 1990, pp. 553-581; y por VelASCO HERNÁNDEZ, F.: «La colonia extranjera de Cartagena en los siglos XVI Y XVII: poder económico y arraigo social», en I Coloquio Internacional «Los extranjeros en la España Moderna», Málaga, 2003, t. I, pp. 681-693. 
autóctona, perteneciente en su mayoría a la vieja oligarquía local. Controlaron el comercio de la barrilla, jabón, seda, aceites, esparto o alumbre, pero también el tráfico de la lana, el crédito, las rentas y la mayor parte de los instrumentos mercantiles y financieros. Posteriormente, en el primer cuarto del siglo XVII, se producirá un relevo generacional, en el que influyó el agotamiento biológico de algunos linajes y la incorporación de nuevas familias de mercaderes que propiciaron una nueva coyuntura de crecimiento económico.

Todo ello redundó en la universalización de las relaciones comerciales de Cartagena que alcanzaron verdadera dimensión internacional. Prácticamente todos los mercados marítimos europeos, con excepción del Mediterráneo Oriental dominado por los turcos (aunque se sostiene un comercio indirecto a través de Marsella y Venecia), estrecharon vínculos económicos con nuestra ciudad, tanto en lo que al comercio de importación se refiere como al de exportación. En este sentido, muchos de los testimonios documentales sobre los que hemos trabajado (sobre todo poderes notariales, cartas de fletamento y seguro, etc.) aluden a un constante desarrollo de los intercambios exteriores desde 1550 , así como a la gran variedad de clientes que negociaban en uno y otro sentido, esto es, como compradores o vendedores.

La relación es intensa con Génova, hacia la que se destinan gran parte de las exportaciones de lana, barrilla, sosa, esparto o seda, e incluso el reenvío de artículos de otros mercados vinculados a Cartagena (dátiles, cera y esclavos de Orán, aceite andaluz y mallorquín, productos coloniales de Sevilla-Cádiz, etc.). Por contra, llegarán de esta procedencia lienzos, sedas elaboradas, rajas y otros tejidos de calidad, cristal, espadas, papel, jabón, quincallería y otras manufacturas ${ }^{21}$.

Este modelo de intercambio se siguió grosso modo con otros puertos italianos, como Livorno o Venecia. El papel veneciano, por ejemplo, se reforzaría a partir del segundo tercio del XVII, cuando el poderío genovés comenzó a flaquear, surgiendo como destino principal de la lana remitida desde Cartagena. Además su especialización en productos de calidad (espejos, cristalería, tejidos finos y caros, cuadros, etc.) le concedió una ventaja añadida en el tráfico con Cartagena y Alicante, las principales puertas de acceso hacia Madrid y Toledo. El resto de Italia tuvo un papel más secundario, excepción hecha de Sicilia, el gran granero del Mediterráneo occidental y zona regular de aprovisionamiento para Cartagena y Murcia ${ }^{22}$.

Francia fue la otra gran protagonista del espacio comercial cartagenero, en cualquiera de sus dos vertientes: la mediterránea y la atlántica. El tráfico con los puertos franceses representó en períodos de paz — hasta 1635- más del 50 $\%$ del registrado en el puerto de Cartagena. La importancia del mercado fran-

21 A.M.C. Caja $251, \mathrm{n}^{\circ} 15$; caja $100, \mathrm{n}^{\circ}$ 9; caja 90, $\mathrm{n}^{\circ} 19$; caja 92, $\mathrm{n}^{\circ} 13$; y A.G.S.; C.M.C., $2^{\mathrm{a}}$ $\mathrm{ep}^{\mathrm{a}}, \mathrm{leg}^{\mathrm{o}} .245$.

22 Velasco Hernández, F.: Auge y estancamiento de un enclave mercantil..., pp. 156-157 y 229232, y Chacón Jiménez, F.: Murcia..., p. 108 
cés se sustentó sobre una oferta muy variada, entre la que se encontraban los cereales, los tejidos, el pescado y toda una suerte de artículos manufacturados y productos caros procedentes del Mediterráneo oriental (vía Marsella). El suministro de cereales se dio indistintamente desde el Mediterráneo (Provenza) y desde el Atlántico (puertos bretones), no así el pescado, en su mayoría procedente de los caladeros del Mar del Norte o de la campaña bacaladera de Terranova ${ }^{23}$. También el lienzo bretón tuvo una presencia destacada en las importaciones cartageneras, al igual que la droguería y especias orientales recibidas de Marsella, desde donde también se suministraban otros artículos manufacturados, como el papel, librería, jabón, tejidos y quincallería. A nivel de puertos destacaron en su relación con Cartagena los de Marsella, Martigues, Six-Fours y La Ciotat en el Mediterráneo y Sait-Malo, Olonne y La Rochelle en el Atlántico ${ }^{24}$.

La conexión francesa se extendía también a un activo comercio de exportación desde Cartagena, en parte estimulado por los propios mercaderes franceses afincados aquí, y que pudo tener su origen en la explotación del alumbre desde finales del siglo XV. A éstos se unieron posteriormente la salida de jabón, esparto, almagre, lana, barrilla, sosa, etc., consignados fundamentalmente a destinos marselleses y bretones.

Con respecto al litoral español, el intercambio de productos fue más limitado, aunque no por ello menos importante. Al norte de Cartagena este tráfico se limitaba a un amplio cabotaje con los puertos catalanes, valencianos y mallorquines. A través de ellos llegaba a nuestra ciudad aceite, queso y cera de Mallorca, y frutos secos, pasas, vino y aguardiente de Cataluña y Valencia. Las ventas desde Cartagena fueron más limitadas puesto que su producción, basada en materias primas industriales, estaba orientada hacia otros mercados.

Al sur de Cartagena, destacó fundamentalmente la estrecha relación con Málaga y Orán. La ciudad andaluza compartía funciones militares y comerciales con el puerto cartagenero, al que también abastecía de aceite, vino y pasas. El contacto con Orán fue muy intenso a lo largo de todo el período: la relación con la aljama judía de este presidio norteafricano era tan fluida que de hecho influyó tanto en el desarrollo comercial de Cartagena como en su estancamiento posterior, sobre todo a raíz su expulsión de Orán en 1669 por el marqués de los Vélez ${ }^{25}$.

23 A.H.P.M. Prot ${ }^{\circ} 5186$, fol. 562 y prot $^{\circ} 5299$, fols. 384 y 399; y A.M.C. Caja 90, nº 33.

24 A.M.C. Caja $95, n^{\circ} 18$ y caja $96, n^{\circ} 6$. El comercio con estos puertos franceses se prolongó en el siglo XVIII, e incluso con un mayor volumen: Archives Nationales de France (A.N.F.), París, affaires étrangères, $\mathrm{B}-1, \mathrm{leg}^{\circ} 360$.

25 A.M.C., caja 98, $n^{\circ}$ 63; caja 85, $n^{\circ} 4$; y A.H.P.M. Prot ${ }^{\circ}$ 5158, fol. 142; prot $^{\circ} 5359$, fol 24; prot $^{\circ} 5360$, fol. 47; 5290, fol. 127; prot $^{\circ} 5170$, fol 86; prot $^{\circ} 5169$, fols. 95-97; prot $^{\circ} 5412$, fol. 157; prot $^{\circ} 5439$, fol. 397; prot $^{\circ} 5430$, fol. 306; prot $^{\circ} 5360$, fols. 30 y 47. Sobre la expulsión de los judíos oraneses, es de obligada lectura: SÁNCHEz BELÉN, J.A.: «La expulsión de los judíos de Orán en 1669», en Espacio, Tiempo y Forma, serie IV, Historia Moderna, 1993, pp. 155-197.

Hispania, LXV/2, núm. 220 (2005) 485-514 


\section{CUADRO 1: PABELLÓN DE ORIGEN DE LAS NAVES} REGISTRADAS ENTRE 1603 Y $1617^{*}$

\begin{tabular}{|c|c|c|c|c|c|c|c|c|c|}
\hline LUGAR ORIGEN & $03 / 04$ & $05 / 06$ & $12 / 13$ & $16 / 17$ & LUGAR ORIGEN & $03 / 04$ & $05 / 06$ & $12 / 13$ & $16 / 17$ \\
\hline -Castilla & & & & & - Francia atlántica & 1 & 7 & 0 & 0 \\
\hline Gibraltar & 2 & 0 & 0 & 0 & Nantes & 0 & 0 & 1 & 0 \\
\hline Huelva & 0 & 1 & 0 & 0 & Olonne & 1 & 26 & 33 & 1 \\
\hline Málaga & 3 & 1 & 1 & 0 & La Rochelle & 1 & 1 & 1 & 0 \\
\hline Motril & 0 & 0 & 0 & 1 & Saint-Malo & 14 & 19 & 18 & 9 \\
\hline$-\underline{R^{\circ} \text { Valencia }}$ & & & & & Brest & 0 & 1 & 0 & 0 \\
\hline Alicante & 0 & 1 & 0 & 1 & S. Juan Luz & 1 & 0 & 0 & 0 \\
\hline Denia & 0 & 0 & 1 & 0 & Calais & 0 & 1 & 0 & 0 \\
\hline Valencia & 1 & 0 & 0 & 2 & Carantec & 0 & 1 & 0 & 0 \\
\hline Vinaroz & 1 & 2 & 1 & 4 & Roscoff & 0 & 2 & 1 & 0 \\
\hline -Mallorca & 1 & 3 & 1 & 0 & El Havre & 0 & 0 & 0 & 1 \\
\hline -Cataluña & 2 & 10 & 5 & 2 & Ruan & 1 & 0 & 1 & 0 \\
\hline Tarragona & 2 & 0 & 0 & 0 & «Bretaña» & 0 & 1 & 0 & 0 \\
\hline Barcelona & 2 & 2 & 24 & 10 & -Portugal & & & & \\
\hline Vilanova & 0 & 0 & 2 & 2 & Lagos & 0 & 1 & 0 & 0 \\
\hline Areyns & 1 & 0 & 0 & 0 & -Inglaterra & & & & \\
\hline Calella & 0 & 1 & 0 & 0 & Plymouth & 1 & 0 & 1 & 5 \\
\hline Canet & 0 & 0 & 1 & 0 & Poole & 0 & 2 & 1 & 0 \\
\hline -Italia & & & & & Fowey & 2 & 1 & 0 & 2 \\
\hline Génova & 8 & 13 & 2 & 6 & Londres & 0 & 1 & 3 & 8 \\
\hline Venecia & 0 & 2 & 0 & 0 & Middlesbrough & 0 & 0 & 2 & 5 \\
\hline Florencia & 1 & 1 & 0 & 0 & Bristol & 0 & 2 & 4 & 0 \\
\hline Pisa & 0 & 0 & 1 & 0 & «Inglaterra» & 1 & 25 & 5 & 6 \\
\hline Isla de Elba & 0 & 0 & 0 & 1 & «Escocia» & 0 & 1 & 0 & 1 \\
\hline -Ragusa & 0 & 0 & 0 & 2 & -Holanda & 0 & 1 & 0 & 3 \\
\hline -Francia medit & 8 & 4 & 2 & 2 & Amsterdam & 1 & 0 & 5 & 11 \\
\hline Marsella & 26 & 31 & 28 & 25 & Hoorn & 0 & 0 & 2 & 7 \\
\hline La Ciotat & 34 & 56 & 23 & 39 & Enkhuizen & 0 & 0 & 4 & 11 \\
\hline Martigues & 11 & 27 & 1 & 19 & Roterdam & 0 & 0 & 1 & 2 \\
\hline Six-Fours & 7 & 37 & 19 & 11 & Breda. & 0 & 1 & 0 & 0 \\
\hline Arles & 1 & 9 & 0 & 0 & Ypres(Flandes) & 0 & 1 & 0 & 0 \\
\hline Saint Tropez & 2 & 12 & 1 & 14 & -Irlanda & 0 & 0 & 0 & 2 \\
\hline Casis & 0 & 5 & 2 & 4 & -Alemania & & & & \\
\hline Toulon & 1 & 12 & 5 & 6 & Hamburgo & 1 & 0 & 3 & 0 \\
\hline «Provenza» & 0 & 53 & 0 & 2 & Norden & 2 & 0 & 0 & 0 \\
\hline «Languedoc» & 0 & 0 & 0 & 1 & Lubeck & 0 & 2 & 0 & 0 \\
\hline Sète & 0 & 0 & 0 & 1 & Riga & 0 & 2 & 0 & 0 \\
\hline Frontignan & 0 & 0 & 0 & 2 & & & & & \\
\hline
\end{tabular}

FUENTE: Velasco HERnÁNDEZ, F.: Auge y estancamiento de un enclave mercantil..., p. 102

Los puertos bajoandaluces representaron un activo muy importante en el comercio cartagenero. Hacia allí se enviaban productos locales y de reexportación, destinados en su mayoría al mercado americano, y desde allí se recibían toda una amplia gama de artículos coloniales, consignados por mercaderes extranjeros afincados en Sevilla y Cádiz, pero vinculados con hombres de negocios de Cartagena (muchas veces emparentados). También este área, junto con 
la portuguesa y gallega eran lugares de origen de buena parte del pescado desembarcado en Cartagena, reexportado en su mayoría hacia el interior castellano. Asimismo, la región lusa complementó, con el complejo Cádiz-Sevilla, la oferta de coloniales llegada a nuestra ciudad.

La relación con los mercados atlánticos restantes fue muy limitada en cuanto al volumen de intercambios, pero además estuvo muy supeditada a las innumerables guerras con la monarquía española. Pese a ello, las embarcaciones holandesas e inglesas tuvieron una importante presencia en nuestro puerto en los períodos de paz, sobre todo las británicas, que llegaron a sustituir a partir de 1635 a otras más tradicionales, como las francesas, raguseas o genovesas. Aún más alejados, los mercados nórdicos o alemanes apenas contaron en el comercio de importación cartagenero, pero no así la región pesquera de Terranova (Canadá), desde donde llegaban periódicamente grandes flotas cargadas de bacalao. Por último, el contacto con América fue siempre indirecto - vía Cádiz, Sevilla o Lisboa-, a pesar de la elección (efímera) de Cartagena por Carlos V como uno de los puertos de trato directo con las Indias. De todas formas, se registraron ocasionalmente algunas experiencias comerciales con la América portuguesa que apenas tuvieron continuidad ${ }^{26}$.

En otro orden de cosas, el análisis de cierta documentación notarial y municipal, como las «escrituras de portes», poderes y obligaciones notariales y contabilidad municipal de carros, bestias y cargas, ha sido fundamental para diseñar a grandes rasgos un mapa de las áreas de influencia del comercio interior cartagenero. En general, podríamos encuadrar los mercados interiores que mantienen relaciones comerciales con Cartagena en una línea imaginaria que penetrando incluso en el sur del reino de Valencia y tomando como vértices Toledo y Madrid, descendería verticalmente hasta Ciudad Real, Andújar, Jaén y Granada. El espacio geográfico así obtenido, que incluso podríamos extender coyunturalmente hasta Sevilla o Medina-Sidonia, conformaría una diversidad de áreas heterogéneas, con grandes contrastes, mal comunicadas con el litoral (excepto con Cartagena-Alicante) y, por tanto, difíciles de penetrar comercialmente. A pesar de estas adversidades, los mercaderes de Cartagena, bien de forma personal o bien a través de factores, apoderados o transportistas, salvaron todo tipo de obstáculos (físicos, políticos, fiscales, etc.) y desde el último tercio del siglo XVI era frecuente su presencia económica en los mercados de todas aquellas tierras. Un elemento esencial, en este sentido, era el tradicional desplazamiento hacia Cartagena de carreteros de las más diversas procedencias a la búsqueda de pescado y mercancías de importación a cambio de trigo, lana, carnes, aceite y otros productos del interior ${ }^{27}$.

26 A.H.P.M. Prot $^{\circ} 5359$, fols. $33-34$ y $371-372$.

27 VelasCo HeRnÁNDEZ, F.: Auge y estancamiento de un enclave mercantil..., pp. 124-129. 


\section{PRODUCCIÓN Y COMERCIALIZACIÓN DE MERCANCÍAS}

Del mismo modo, y en lo que a mercancías traficadas se refiere, debemos hablar de generalidad. Prácticamente toda la gama de artículos consumibles en aquellos tiempos deambularon en mayor o menor medida por el puerto cartagenero. Quizá aquí debemos llamar la atención sobre el enorme volumen importador de productos de lujo y manufacturas procedentes de algunos mercados europeos. En este punto eran las repúblicas italianas (Génova y Venecia, principalmente) las que suministraban un amplio elenco de tejidos de calidad, cristalería, joyería, cuberterías de plata, espejos, espadas, herramientas, etc., pero también droguerías, especias de oriente y otras. Debemos destacar también la participación marsellesa, con droguería y objetos industriales, y al mercado esclavista de Orán, desde donde Cartagena se surtía, además de los citados esclavos, de cera, dátiles, cueros y cereales ${ }^{28}$.

Un comercio de importación trascendental para nuestra ciudad fue el abastecimiento constante de trigo desde los graneros siciliano, provenzal y bretón, que paliaban en el enorme déficit productivo de nuestra comarca y de otras más alejadas, como la Mancha o la alta Andalucía, tradicionales regiones frumentarias. También fundamental, dado el enorme auge de la industria jabonera de Cartagena, fue la importación masiva de aceite desde las ciudades andaluzas, tanto del interior (Baeza, Ubeda, Arjona, Jáén) como del litoral (Almería, Málaga, Almuñécar), y de otros puertos mallorquines y valencianos $^{29}$. De igual manera, no queremos dejar pasar la trascendencia del mercado de productos americanos, centralizados en el binomio Sevilla-Cádiz y en la capital portuguesa, con los que nuestros mercaderes mantuvieron estrechísimas relaciones, incluso tentativas de participación directa en él, como la llevada a cabo por el capitán Julián Jungue.

La magnitud de este tráfico portuario nos hace suponer, como es obvio, que sólo una pequeña parte de los productos que se descargaban en el puerto de Cartagena o circulaban por su jurisdicción se quedaban en la ciudad. La Cartagena del Siglo de Oro no era un gran centro de consumo, como lo eran otras ciudades portuarias italianas o españolas, caso de Barcelona, Valencia, Sevilla o Málaga, pues apenas contaba con algo más de 6 u 8.000 habitantes; no poseía asimismo una élite nobiliaria y, clerical digna de tener en cuenta; ni siquiera su nutrida colonia de mercaderes tenía capacidad para absorber la llegada masiva de productos suntuarios, exóticos o simplemente caros, procedentes del exte-

28 El intenso tráfico con Orán no pasaba desapercibido para el Almojarifazgo de Sevilla, encargado de administrar la aduana de Cartagena. Según éste, «viene al dicho puerto (de Cartagena) de Orán gran suma de cera, dátil, corambre, pluma y otras diferentes mercaderías» (Biblioteca Nacional, Madrid, Copia de los puertos y lugares conprendidos en la renta de los almojarifazgos de Sevilla..., manuscrito $13.212, \mathrm{n}^{\circ} 165$ ).

29 Archivo de la Real Chancillería de Granada (A.R.Ch.G.), cab ${ }^{a} 511, \mathrm{leg}^{\circ}$ 2.218, $\mathrm{n}^{\circ} 7$; A.M.C. Caja 97, ${ }^{\circ} 21$, caja 97, $\mathrm{n}^{\circ} 21$ y A.H.P.M. Prot ${ }^{\circ}$ 5257, fol. 293; $\operatorname{prot}^{\circ}$ 5290, fol. 67.

Hispania, LXV/2, núm. 220 (2005) 485-514 
rior. Lo que realmente extradimensionaba su capacidad mercantil, aparte de la actividad de la Proveeduría de Armadas, el mantenimiento de los presidios africanos y el abastecimiento de las embarcaciones llegadas al puerto - que podían provocar en momentos puntuales una sustancial alteración del ritmo económico diario - era el rol que fue adquiriendo desde los inicios de la Modernidad como abastecedora y reexpendedora hacia el interior de los artículos llegados a sus muelles, a la vez que salida fundamental de las producciones de aquellas tierras hacia el exterior.

Pero al contrario de Valencia, por ejemplo, el comercio cartagenero no se limitó fundamentalmente a la faceta importadora, sino todo lo contrario. Precisamente nuestra ciudad alcanzará cierta especialización en la exportación de materias primas, cuyo protagonismo arranca desde los últimos tiempos medievales con la salida de abundantes partidas de lana y alumbre. $Y$ aunque el alumbre cerrará su ciclo productivo a finales del siglo XVI, nuevas materias primas abundantes en nuestra comarca, como la sosa, barrilla, esparto o almagre, le sucederán con gran acierto en los principales mercados europeos. Todo ello complementado con algunas iniciativas industriales, como las fábricas de jabón y bizcocho, tenerías e industria del salazón instaladas en ella y que diversificaron aún más la oferta productiva y exportadora cartagenera.

\section{PRINCIPALES AgENTES DEL CAMBiO: LA BURGUESÍA MERCANTIL INSTALA- DA EN CARTAGENA}

El avance extraordinario de Cartagena no se hubiera podido concretar sin la participación decisiva de una activa colonia de mercaderes, de diversas procedencias y nacionalidades, que fue tomando posesión de todos los resortes económicos de un área geográfica, como el Sureste español, en plena expansión. Por ello, es imposible comprender el auge comercial experimentado por nuestra ciudad sin valorar adecuadamente el papel fundamental jugado por la burguesía mercantil, tanto autóctona como de origen extranjero, en la apertura de este enclave portuario - y del reino de Murcia, por añadidura - a las grandes líneas del tráfico internacional, en un proceso creciente de extroversión económica. Nada mejor que la amplia representación consular establecida en Cartagena para certificarlo. De hecho, como señaló en su día Kamen, a los principales centros comerciales de España se les podía identificar por la presencia de un cónsul extranjero, y Cartagena llegó a tener prácticamente de todas las nacionalidades marítimas ${ }^{30}$.

30 KAMEN, H.: La España de Carlos II... , p. 227. Cartagena llegó a tener, entre otros, los consulados de las siguientes naciones: Génova, Francia, Inglaterra, Holanda, Alemania, Venecia, Nápoles y Ragusa (VELASCO, F.: Auge y estancamiento de un enclave mercantil..., pp. 436-443.

Hispania, LXV/2, núm. 220 (2005) 485-514 
Un punto de partida muy aproximado nos lo da la averiguación hecha por el Consejo de Hacienda sobre el estado del vecindario de Cartagena tras la epidemia de peste de 1559 , que ya la altura de 1560 constataba la existencia en la ciudad de «hasta treynta tratantes, ansi vezinos como ginoveses y forasteros, los quales tratan por mar y por tierra en muchos generos de mercaderías...» ${ }^{31}$. Esta documentación no hacía sino corroborar la presencia de un importante movimiento mercantil en torno a la ciudad y área portuaria con síntomas de gran vitalidad. Hacia esa fecha se cerraba un primer período de asentamiento de comerciantes extranjeros, caracterizado por la figura del mercader transeúnte, sin avecindar, y que vivía a caballo entre los puertos de Alicante y Cartagena. Sin embargo, esta situación cambia definitivamente hacia 1570 , cuando los avecindamientos de extranjeros comienzan a realizarse de forma masiva. La fuerte resistencia de la oligarquía municipal a la concesión de vecindades fue vencida con determinadas estrategias. Una de las más repetidas era la concesión de cartas reales de naturaleza a través de su influencia en la Corte, de forma parecida a lo que en Sevilla llevaban a cabo los mercaderes flamencos, tal como confirmó Stols. Pero lo común fue la adquisición del estatuto de vecino tras cinco o diez años de residencia, con un hogar familiar establecido. Detrás del interés por esta nueva condición social se escondían importantes beneficios económicos derivados de las exenciones fiscales de los habitantes de Cartagena.

Consolidadas, por tanto, las colonias genovesa y castellana en Cartagena hacia 1560-1590, a las que seguirán la provenzal, bretona, portuguesa, etc., los negocios financieros y mercantiles se multiplicaron en constante progresión, abriendo nuevas cuotas de mercado e internacionalizando la economía local y regional. Braudel nos enseñó como el espacio del mercader tiende a redondearse rápidamente si la época en la que actúa está bajo el signo de la expansión (se contrae en el caso contrario), sobre todo si se une a los grandes negocios, el uso de letras de cambio, monedas, metales preciosos, etc. ${ }^{32}$. Esta circunstancia se percibe fácilmente a la hora de abordar las trayectorias personales de los grandes mercaderes cartageneros, pues en casi todos los casos encontramos un buen número de poderes a sus corresponsales en ciudades muy alejadas de Cartagena para el cobro de numerosas deudas aplazadas, transporte y venta de productos varios, expedición de letras de cambio, etc. Desde ese momento hablamos, por tanto, de una economía de mercado - o de mercados-, cuyo soporte principal sería el espacio marítimo, sin olvidar las importantes conexiones con los grandes centros peninsulares de consumo, como era el caso de Madrid, Toledo, Granada, Valladolid o Sevilla.

Entre todos ellos destacaron por su número e importancia específica los genoveses, con mucho el grupo más activo de cuantos negociantes de una y otra na-

31 A.G.S. Consejo y Juntas de Hacienda, legs. 37-47.

32 BRAudel, F.: Civilización material, Economía y Capitalismo, siglos XV-XVIII, Madrid, 1984, t. II, pp. 151-2.

Hispania, LXV/2, núm. 220 (2005) 485-514 
cionalidad recalan en el ámbito cartagenero de los siglos XVI y XVII. Su presencia en la ciudad puede rastrearse desde los tiempos de Alfonso X el Sabio, con cierta continuidad durante la Baja Edad Media ${ }^{33}$. Pero será en los treinta últimos años del siglo XVI y primeros del XVII cuando la inmigración de estos mercaderes italianos se tornó masiva. Un buen número de ellos vinieron atraídos por las amplias exenciones fiscales que gozaban los vecinos de Cartagena dentro y fuera de la ciudad, otros tantos aprovechando los contactos con algún familiar instalado aquí o en las zonas próximas y, otros muchos, como simples «factores» de grandes mercaderes residentes en otras plazas comerciales, pero con intereses en ésta. La colonia genovesa no dejó de incrementarse durante este siglo XVII; se ganará en número pero también en calidad: a una primera generación de grandes mercaderes, como Pedro Francisco Panesi, Esteban Espínola, Tomás y Franco Diguero, Gregorio Monleón, Esteban Ferreto, Octavio Mayoli o Jácome y Octavio Corvari, sucederá otra no menos importante, formada por las sagas - ya no individualidades - de los Panes, Rato, Tacón, Lamberto, Fravega, Capelo, Bartolotto y otros muchos ${ }^{34}$.

Pero no sólo genoveses, también los mercaderes de otras nacionalidades cobraron cierto relieve dentro de la economía cartagenera. De hecho, la documentación notarial y municipal abunda en la actividad de algunos milaneses, o de un pequeño grupo de mercaderes portugueses que trafican con lana, paños y trigo, pero sobre todo, de un buen número de franceses, en su mayoría de origen bretón o provenzal, cuyo valor individual puede compararse a los de los grandes mercaderes italianos ${ }^{35}$. También algunos escasos flamencos e ingleses, cuyos negocios sufrieron en algunas etapas las consecuencias del enfrentamiento militar con España, circunstancia a la que se unieron a partir de 1635 los comerciantes franceses. Napolitanos, raguseos, venecianos, e incluso alemanes, completaron el elenco mercantil de carácter extranjero afincado en Cartagena.

No queremos olvidar en esta relación a los hombres de negocios castellanos, muchos de ellos descendientes de conversos de Toledo o Medina, y cuya mejor aportación a nivel económico será la conexión Toledo-Cartagena-Orán. Todos ellos constituyeron una nómina mercantil que en sus mejores momentos pudo acercarse a los 200 miembros, entre pequeña y gran burguesía, lo que suponía casi un $15 \%$ de los vecinos de la ciudad.

Una gran parte de esta burguesía acabó arraigando en Cartagena y desde muy temprano buscó el acceso al poder político y su posterior ennoblecimiento ${ }^{36}$.

33 TORres FonTes, J.: «Genoveses en Murcia (Siglo XV)» y Molina Molina, A.L. «Mercaderes genoveses en Murcia en la época de los Reyes Católicos», ambos publicados en Miscelánea Medieval Murciana, vol. II (1976), pp. 71-168 y 283-308.

34 Archivio di Stato, Génova (A.S.G.), Literarum, reg. 57-1833, $\mathrm{n}^{\circ} 113$; Lettere Consoli Spagna, 5-2.674; y Giunta di Marina, f. 2.

35 A.N.F., París. Estado, serie K, legs. 1.440 y 1.453.

36 Para un mayor conocimiento del tema, véase: VeLASCO HERNÁNDEZ, F.: «Lazo familiar, conexión económica e integración social: La burguesía cartagenera de origen extranjero en el siglo XVII», 
Sin embargo, no fue fácil la inserción de esta nueva clase mercantil en la jerarquía social de la ciudad. Los problemas y los roces se multiplicaron cuando los genoveses se introdujeron en las tradicionales fuentes de riqueza del viejo patriciado urbano, esto es, en la explotación agraria, la compraventa de lana, los arrendamientos de rentas y otros. La situación conflictiva se agravó aún más desde el momento en el que los mercaderes accedieron a los órganos de poder, compartiendo con la antigua oligarquía el dominio del Concejo. Sin embargo, esta no fue la forma común que imperó durante el siglo XVII, sino que, al contrario, hubo una lenta pero continua integración desde las primeras décadas de ese siglo, como atestiguan la gran cantidad de matrimonios mixtos entre ambos grupos. Aunque la escena política fue en un principio un terreno vedado a todo aquel que no procediera de los viejos linajes, desde finales del siglo XVI se produjo un proceso lento, pero continuado, de infiltración en las estructuras políticas de la ciudad y en especial en su principal órgano rector: el Concejo. El impacto inicial fue violento, pero no llegó a interrumpir el proceso de inserción. El viejo patriciado se vio incapaz, a todos los efectos, de frenar la intromisión del grupo mercantil en los órganos dirigentes, pues su poderío económico seducía con más facilidad de la esperada a una Corona con ciertas estrecheces económicas y que tenía en la venta de cargos un excelente recurso fiscal, sobre todo en el reinado de Felipe IV.

Precisamente en este punto es necesario reflexionar sobre la enorme trascendencia que tiene el progresivo control de los órganos de gobierno municipales por parte de una burguesía no castellana, venida del extranjero, que a mediados del mismo supone entre el 40 y el $60 \%$ de su composición. Quizá sea esta una de las pocas experiencias en este sentido, junto a Cádiz y Sevilla —y posiblemente Málaga - que se conocen en la Castilla del Antiguo Régimen ${ }^{37}$.

Parte de los elementos del grupo burgués permanecieron fieles a su condición mercantil. Sin embargo, otros buscaron desde su llegada el acceso a la hidalguía, esto es, la promoción nobiliaria. La mayoría de ellos se sirvieron del matrimonio para conseguir su fin, aunque muchos otros procedían de familias hidalgas, cuyo estatuto estaba reconocido en sus ciudades y países de origen, pero que aquí era necesario certificar. Así, desde comienzos del siglo XVII los cruces con la oligarquía seminobiliaria local, aquella vieja aristocracia de terratenientes y ganaderos, comenzaron a darse de forma lenta al principio, pero con cierta aceleración desde la segunda mitad del XVII, a partir de la cual se convirtieron en un hecho habitual ${ }^{38}$. En definitiva, pues, al contrario que en las

en Historia de la Familia. Nuevas perspectivas sobre la Sociedad Europea, v. IV, Murcia, 1997, pp. 220-239, y «Comportamientos y estrategias sociofamiliares de la burguesía mercantil de Cartagena en los siglos XVI y XVII», en Familia, transmisión y perpetuación (siglos XIV-XIX), Murcia, 2002, pp. 221-239.

37 VELASCO HernánDEZ, F.: «La colonia extranjera de Cartagena en los siglos XVI Y XVII..., t. I, p. 691.

38 Entre las familias genovesas que entroncaron con oligarquía cartagenera o murciana, cabe destacar los apellidos: Panesi, Graso, Arezio, Fravega, Baldasano, Rato, Lamberto, Tacón, Digueri, 
viejas ciudades castellanas, la promoción interestamental fue relativamente asequible para los mercaderes enriquecidos, tanto de origen extranjero como de origen local. En consecuencia, el enlace matrimonial con el viejo patriciado o la compra de señoríos, títulos, etc., fueron las fórmulas más usadas por la burguesía de esta ciudad para conseguir la hidalguía. A partir de aquí, los más poderosos intentaron medrar hacia posiciones más elevadas, haciéndose rodear de la nobleza murciana de mayor estirpe o de la alta aristocracia castellana vinculada a la Marina. Existió, en consecuencia, cierta tendencia de una parte de la burguesía hacia el ennoblecimiento, por eso, fue difícil encontrar grandes dinastías mercantiles que superasen las tres generaciones, como parece ser una regla en toda Castilla. La adquisición de propiedades rústicas y urbanas y la inmovilización, por consiguiente, de capitales, fue la nota predominante entre esta burguesía mercantil enriquecida.

\section{LOS OBSTÁCULOS INHERENTES: FISCALIDAD, CONTRABANDO Y CORSO}

Comercio y fiscalidad han formado siempre un "matrimonio poco avenido", consustancial a la propia dinámica económica y a la necesidad de recursos por parte de las administraciones. Desde nuestra perspectiva, y como punto de partida, podemos decir que Cartagena fue objeto de una auténtica persecución fiscal durante la mayor parte del período que aquí estudiamos, sobre todo, una vez confirmado su desarrollo económico. Dicha escalada fiscal se fue materializando a través de un claro proceso de acoso y derribo sobre esta experiencia mercantil única en Castilla, que basó su desarrollo en la exportación de determinadas materias primas, como la lana y la barrilla, y en la importación de productos alimenticios y manufacturas destinados al inmenso interior hispano. Ėste proceso se tradujo en un aumento permanente de su contribución por alcabalas (casi se quintuplicó en menos de 50 años), en la introducción de nuevos impuestos, como los millones y los cientos, en la petición constante de donativos, ventas de oficios, annatas, etc. ${ }^{39}$.

Aunque la nota general en la Castilla de los siglos XVI y XVII fue el incremento constante de la presión fiscal, especialmente en Andalucía, reino de Murcia y algunas ciudades del interior, como Madrid o Valladolid, no todos los lugares fueron medidos de la misma forma. Hoy día sabemos que a muchas localidades del interior les fueron concedidas rebajas, tanto en sus encabeza-

\footnotetext{
Imperial, Machavelo, Çiguera, Cacholo, Corvari, Blanquete, Bosomo, Fabri, Pereti, Lardón, etc.; todos ellos mercaderes o descendientes de ellos, cuyos apellidos fueron castellanizados en muchos casos (Archivo Parroquial de Santa María de Gracia, Cartagena, libros de matrimonios números 2, 3, 4 y 5 , años 1593-1694).

39 Este tema ha sido desarrollado más ampliamente en: VELASCO HERNÁNDEZ, F.: «La presión fiscal del siglo XVII en el reino de Murcia: viejas y nuevas figuras tributarias», en Espacio, Tiempo y Forma, Serie IV, $\mathrm{H}^{\mathrm{a}}$ Moderna, t. 15 (2002), pp. 85-104.
}

Hispania, LXV/2, núm. 220 (2005) 485-514 
mientos de alcabalas, tercias y cientos como en el pago de los millones. Otras muchas congelaron e incluso disminuyeron su contribución. Incluso dentro del reino de Murcia, las ciudades de realengo tuvieron distinto tratamiento en su cuota de alcabalas. De hecho, hemos podido comprobar como Cartagena fue la peor tratada del realengo murciano - que en su conjunto también salió mal parado-, probablemente porque para el Consejo de Hacienda las ciudades portuarias tenían fama de ricas por el comercio. Sin embargo, podemos encontrar excepciones: Cádiz, espejo del comercio con las Indias, le fue incrementado su encabezamiento de alcabalas entre 1587 y 1611 sólo un 10,38\% (desde 2.814.000 hasta 3.106.210 maravedís), mientras que a Cartagena se le aumentó en un $184,83 \%{ }^{40}$. Otros puertos próximos como Almuñécar, Motril, Salobreña y Almería contribuían también con cantidades muy pequeñas.

Pero no sólo hubo una persecución fiscal por parte de la Corona, también la oligarquía municipal de Cartagena decidió cargar sobre la actividad mercantil - al calor de la bonanza económica - el peso de los tributos locales. Bien es cierto que algunos de los impuestos, como las alcabalas, fundamentaban su propia naturaleza en la compraventa de artículos en general, pero otras muchas, como las municipales (la renta mayor, correduría de carros, almotacenía, ancoraje, saca de pescado, mollajes, sisa y cabezaje) y las de nueva creación (los primeros millones, donativos, censo de Juan Bta. Preve, etc.) fueron también transferidas hacia el tráfico y comercio portuario. Por tanto, era lógico que cuando el principal nervio de la ciudad comenzara a flaquear, como así ocurrió a partir de la década de 1640, el edificio fiscal montado en torno a él empezará a tambalearse; más aún, cuando las posibilidades de buscar otras fuentes alternativas de recursos fiscales parecían prácticamente imposibles en una población venida a menos. Por ello, no es de extrañar que en momentos puntuales se produjeran fuertes tensiones sociales, como en 1648 y 1683 (en este último caso desembocó en una autentica revuelta popular) que suponían claros toques de atención a unas autoridades acostumbradas a imponer toda suerte de tributos e incrementar los ordinarios, sin ofrecer ningún tipo de contrapartida ${ }^{41}$.

Como en muchas otras ciudades portuarias, las actividades contrabandistas se manifestaron en Cartagena con cierta frecuencia y en sus dos facetas más conocidas: como tráfico de artículos vendidos sin previo pago de los impuestos y derechos de aduana, y como introducción o salida fraudulenta de mercancías prohibidas. Este contrabando fue en aumento a medida que creció la presión fiscal sobre los principales productos objeto de comercio, así como el aumento de la vigilancia en la salida de moneda de plata.

En líneas generales, el contrabando ofrece en Cartagena dos caras bien diferenciadas, según se trate de una actividad con apariencia legal o, por el contra-

40 A.G.S. Cont. Grles., legs. 3.896 y 3.890.

41 Los sucesos de 1683 han sido estudiados con todo lujo de detalles por J.A. SÁNCHEZ BELÉN y A. AlCARAZ HERNÁNDEZ: «Oligarquía municipal e impuestos: la asonada del campo de Cartagena en 1683, en Espacio, Tiempo y Forma, serie IV, t. IV (1991), pp. 163-202. 
rio, con una fisonomía declarada absolutamente ilícita. Existía, en consecuencia, un distinto tratamiento para una actividad más o menos similar: de un lado, un contrabando claramente permitido, que se ejercía de diversas formas, y de otro, el no permitido, que se centraba casi de forma exclusiva en los no vecinos y, sobre todo, en los extranjeros.

El permitido o admitido basaba su propia naturaleza en las enormes franquicias y exenciones de los vecinos de Cartagena y que les otorgaba cierta condición de habitantes privilegiados en una especie de «puerto franco» para ellos y sus clientelas. De hecho, en muchísimos negocios solían figurar como auténticos testaferros de otros mercaderes extranjeros o no avecindados, que los utilizaban para evadir los gravosos impuestos castellanos. Con el tiempo, muchos de estos mercaderes accedieron a la condición de vecino y con ello a los beneficios fiscales que se derivaban de ella. Pero además, a los avecindados en Cartagena no se les solía inspeccionar el dinero o mercancías que sacaban de la ciudad, ni les alcanzaba la jurisdicción de la Alcaldía de sacas y cosas vedadas, ni la de los Puertos Secos, ni el Almojarifazgo, y ni siquiera muchos de los portazgos o aduanas del interior de Castilla. Esta era una situación conocida por los agentes fiscales, de ahí el enorme recelo que despertaban los mercaderes de Cartagena en los puestos de aduana castellanos, donde muchas veces eran retenidos hasta que se comprobaban los privilegios y franquicias de la ciudad (el Concejo enviaba copias con comisionados).

El contrabando no permitido era más inflexible y su persecución era estimulada periódicamente desde la Corona. Las denuncias en este apartado son numerosas y se reflejan en multitud de testimonios recogidos por la justicia ordinaria y la alcaldía de sacas. Por lo general, no suelen tratarse de denuncias importantes, tanto en su cuantía como en la calidad de la mercancía defraudada: pequeñas cantidades de dinero, artículos de droguería y quincallería, bizcocho, seda, etc. Pero la situación se magnificaba de forma considerable cuando intervenían extranjeros, en especial si procedían de países enemigos o infieles. Ingleses, holandeses o franceses tuvieron, en este sentido, auténtica fijación sobre el artículo de contrabando más perseguido, con diferencia, en Castilla: la moneda de plata, que escapaba de muy diversas maneras de la circulación habitual. En este punto los delitos se repiten con harta frecuencia y en ellos participaban casi siempre comerciantes, capitanes y marineros de esas nacionalidades, que eran sorprendidos por las autoridades cuando procedían a embarcar las monedas de plata que captaban en la ciudad.

Como vemos en el cuadro $\mathrm{n}^{\circ} 2$, el tráfico ilegal de moneda era el elemento más destacado del contrabando cartagenero, al menos hasta la generalización de las prácticas devaluatorias y los resellados en los reinados en Felipe III y Felipe IV. Es posible que Juan Andrea Doria hablara de la seguridad de Cartagena sobre Barcelona para sacar el dinero oficial con un doble sentido, debido al enorme arraigo que estas prácticas tenían entre sus habitantes y allegados ${ }^{42}$.

42 Braudel, F.: El Mediterráneo..., t. I, p. 648. 
Pero éstas también fueron acompañadas por muchas otras «sacas», en apariencia legales, y que practicaban los comerciantes y marinos de Cartagena en sus frecuentes traslados a Orán, a los puertos del reino de Valencia, a las ciudades italianas o los enclaves del Golfo de Cádiz, y que fueron raramente perseguidas por las autoridades competentes.

\section{CUADRO 2: ALGUNAS DETENCIONES POR CONTRABANDO EN 1599 Y 1605}

\begin{tabular}{|c|c|c|}
\hline FECHA & ORIGEN DEL CONTRABANDISTA & MERCANCÍA/s \\
\hline $18-12-1598$ & Reino de Valencia & Dinero \\
$19-01-1599$ & Francia & Dinero \\
$06-03-1599$ & Reino de Valencia & Dinero \\
$08-11-1599$ & Francia & Dinero \\
$16 / 28-11-99$ & Francia & Dinero \\
$28-08-1605$ & Francia & 9.700 reales. \\
$17-10-1605$ & Inglaterra & 174 reales. \\
$04-11-1605$ & Inglaterra & «moneda en cuartos» \\
$05-11-1605$ & Bretaña (Francia) & 89 reales \\
$04-12-1605$ & Málaga & arrobas de cáñamo \\
$18-01-1605$ & - & 51 reales \\
$13-01-1606$ & Francia & 708 reales \\
\hline
\end{tabular}

Fuente: Velasco Hernández, F.: Auge y estancamiento de un enclave mercantil..., p. 369.

Sin embargo, desde los últimos años del reinado de Felipe III, el contrabando de dinero va perdiendo protagonismo en beneficio de otros artículos muy gravados, como es el caso de la sosa, la barrilla, la lana o el pescado.

De todas formas, aunque el contrabando de moneda se mantuvo a lo largo de todo el período, acabó siendo superado por el de mercancías. En la exportación fraudulenta de mercancías, la estela dejada por la venta ilegal de trigo, cebada o pescado fue continuada a lo largo del siglo XVII por la salida de numerosas partidas de sosa y barrilla no controladas por Hacienda. La presión fiscal fue una vez más la responsable del incremento súbito de este contrabando, cuya incidencia se multiplica a partir de 1621, al revertir sobre ella un impuesto tras otro. Una situación fraudulenta que se mantuvo - y más bien se incrementó- durante la segunda mitad del siglo XVII, como confirma una consulta del Consejo de Hacienda de 24 de noviembre de 1689 en la que se admite que desde las playas murcianas se extraía gran cantidad de barrilla de forma ilegal, que por su magnitud requirió en algunas ocasiones - como en 1684 - el empleo del propio ejército para erradicar este contrabando ${ }^{43}$.

43 SÁNCHez BelÉN, J.A.: La política fiscal de Castilla durante el reinado de Carlos II, Madrid, 1996 , pp. 128 y 172. 
En otro orden de cosas, el Mediterráneo constituía un medio muy peligroso, donde el corsarismo y la piratería, con una larga tradición, habían arraigado entre los habitantes de sus riberas, constituyendo un lucrativo negocio para muchas ciudades portuarias, especialmente las de religión islámica. Si bien Cartagena tuvo cierta tradición corsaria durante la Baja Edad Media, la situación comenzó a invertirse desde mediados de la centuria siguiente cuando el peligro turco y argelino comenzó a hacer acto de presencia en nuestra costa. Los momentos más apurados coincidirán con las dos etapas de esplendor vividas por el «gran nido de piratas y corsarios» establecidos en Argel durante los años 156070 y $1580-1620^{44}$. De hecho, nunca hasta entonces, se había visto el litoral murciano tan agredido por embarcaciones de procedencia islamita. Pero, aunque en la mayoría de los casos no pasó de la simple alarma, en muchos otros las incursiones causaron una importante sangría humana en agricultores, ganaderos y pescadores.

\section{CUADRO 3: ALGUNAS ACCIONES DE ANTICORSO REALIZADAS POR VECINOS DE CARTAGENA}

\begin{tabular}{|l|l|l|}
\hline FECHA & LUGAR & BOTÍN CAPTURADO \\
\hline 1567 & Calnegrete & 80 turcos, ropas, armas y 1 galeota \\
1590 & Cala del Fraile & Recuperación de una nave cristiana \\
1600 & Costa de Cartagena & Varios moros y una galeota \\
1609 & Santa Pola-Isla Grossa & 16 moros, 2 cautivos y 1 bergantín \\
1611 & Cala del Hornillo & Varios moros, 5 cautivos, 1 bergantín \\
1616 & Cala Bardina & 15 moros, 1 renegado y un bergantín \\
\hline
\end{tabular}

Fuente: Velasco HernándeZ, F.: Comercio y actividad portuaria en Cartagena ..., p. 142.

Remitiéndonos a los años iniciales del esplendor argelino, encontramos por primera vez constancia de actividades corsarias en el año 1567, fecha en la cual cuatro galeras comandadas por el capitán Gil de Andrade, con vecinos de Cartagena a bordo, capturan una importante presa en Calnegre ${ }^{45}$. Después de esta fecha se suceden de forma intermitente diferentes noticias sobre acciones anticorso, con diversa fortuna. En algunos casos, como en las efectuadas en 2 de junio de 1609 y 7 de enero de 1616, el botín conseguido fue bastante copioso, tanto en hombres como en mercancías: en la primera, además del bergantín que los transportaba, atraparon 16 moros y 2 cautivos cristianos; en la segun-

44 BRAUdel, F.: El Mediterráneo..., t. II, pp. 304-311.

45 Velasco HernándeZ, F.: «Un obstáculo a la < pax hispánica > de Felipe III: la pervivencia del corsarismo islámico en el Levante y Andalucía», Ponencia de las $V$ Jornadas sobre fortificaciones, piratería y corsarismo en el Mediterráneo, Cartagena, 2002 (en prensa).

Hispania, LXV/2, núm. 220 (2005) 485-514 
da, fue igual el número de moros capturados, aunque uno de ellos era renegado. En otras ocasiones, la acción no quedó más que en una simple «cabalgada», sin otro éxito que la huida de la embarcación mora, aunque a veces, tal y como ocurrió en mayo de 1590, dejarán tras su fuga una nave de mercancías cristiana atrapada por aquellos previamente.

La vertiente lucrativa del corsarismo llevó a algunos mercaderes y marinos cartageneros a participar con capitales y barcos en la organización de expediciones a las costas africanas. Uno de ellos fue el bretón Julián Launay, quien en 1605, por ejemplo, pagó a Claudio Forest 1.100 reales, para armar la fragata «Santa Ana», del cartagenero Alonso Montesinos. Otros comerciantes, como Luis de Requena y Jaime Ros, fletaron también ese año la fragata de García de Oviedo para marchar a la costa africana en $\operatorname{corso}^{46}$. Con todo, lo que entendemos por corso no ejerció en Cartagena el verdadero sentido de negocio que en otras ciudades ribereñas, como Argel o Mallorca, sino que, lejos de ello, estuvo motivado por la necesidad de defenderse de las frecuentes incursiones de los piratas y corsarios musulmanes, que cautivaban parte de la población y entorpecían el tráfico mercantil de la ciudad. El corso cartagenero era especialmente un corso anticorsario o defensivo. De hecho, podemos afirmar con rotundidad que en el negocio esclavista de la ciudad la mayor parte de los ejemplares vendidos procedían de Orán, hacia donde eran atraídos por los intermediarios judíos afincados en este presidio africano.

\section{CONCLUSIÓN: ¿UN MODELO SINGULAR?, ¿CRISIS O ESTANCAMIENTO DE ESE MODELO?}

Estos son grosso modo los detalles más importantes en los que se basó el despegue económico de Cartagena en el período comprendido entre la segunda mitad del siglo XVI y primera del XVII. Una expansión económica que se apoyó fundamentalmente en la explotación de un modelo socioeconómico basado en la actividad comercial generada desde su puerto. Un modelo que no creemos singular en lo general, pues repite en gran parte lo visto en Alicante, Málaga o Cádiz, pero si ofrece unas peculiaridades propias que no debemos perder de vista (fuerte impacto de la presión fiscal, exclusión del tráfico de Indias, relación intensa con Italia y los Presidios africanos, estrecha vinculación con Madrid y Toledo, importancia de lo militar, etc.).

Pero en nuestro caso, ¿porqué se estancó o entró en recesión mediado el siglo XVII?. Es evidente que ni el momento ni la situación nacional o internacional acompañaban. Recuérdese que hacia esos años la Monarquía hispánica de Felipe IV pasaba por enormes apuros que amenazaban su desintegración, tanto en el plano interior (con las separaciones de Cataluña y Portugal o las

46 A.H.P.M. Prot ${ }^{\circ} 5.287$, fols. 196 y 215. 
sublevaciones de Andalucía, Aragón, Sicilia y Nápoles), como en el exterior, donde la entrada de España en la Guerra de los Treinta Años, el enfrentamiento con Holanda y la nueva y larga contienda con Francia ponían en pie de guerra permanente a todos los súbditos de la Corona. Sin embargo, los motivos fundamentales de este estancamiento fueron de índole económico y político. Y en estos dos apartados debemos de otorgar toda la responsabilidad a varios hechos que consideramos trascendentales: la enorme competencia del vecino puerto de Alicante, con unas condiciones impositivas y materiales muy ventajosas, la influencia perniciosa de una coyuntura bélica muy nociva para la actividad mercantil y, sobre todo, la enorme presión fiscal que tuvo que soportar Cartagena después de la entrada de España en las guerras del siglo XVII, que la convirtieron en un puerto demasiado caro y poco atractivo para la burguesía mercantil, además de otros muchos que podemos considerar secundarios.

La gran diferencia tributaria entre Cartagena y Alicante fue uno de los aspectos determinantes del estancamiento cartagenero. La autonomía fiscal de los territorios forales como el valenciano, que la Unión de armas de Olivares no pudo alterar, se manifestaba en un régimen tributario diferente al de Castilla, muchísimo más gravoso (que Gutiérrez Nieto calculó en un $700 \%$ desfavorable para los castellanos ${ }^{47}$ ). Esta débil fiscalidad favoreció de forma notoria las actividades mercantiles en la vecina Alicante, cuyo valor se reforzaba por su proximidad a Castilla, la buena comunicación con Madrid-Toledo y Andalucía y su excelente situación frente a las principales rutas del Mediterráneo. En esa ciudad, al igual que en Cartagena, se fue instalando una poderosa colonia de mercaderes extranjeros que potenciaron notablemente su desarrollo comercial. Así, durante la segunda mitad del siglo XVI y comienzos del XVII se estableció entre ambas una fuerte rivalidad interportuaria, cuyo equilibrio se rompió definitivamente en favor de Alicante con la entrada en escena de la «fiscalidad de guerra» de Felipe IV. En una fácil relación causa-efecto, el declive de una (Cartagena) fue seguido del ascenso vertiginoso de la otra (Alicante), hasta convertirse en uno de los principales puertos españoles en el reinado de Carlos II, tal como hemos visto al principio.

La coyuntura bélica internacional y la recesión de los viejos emporios del Mediterráneo occidental fueron también factores decisivos en el estancamiento cartagenero. Aunque las guerras internacionales de nuestra monarquía, en su mayoría contra potencias marítimas (Holanda, Inglaterra y Francia; en este último caso nuestro mejor cliente, con más de un $50 \%$ del tráfico portuario), hundieron gran parte de la actividad portuaria de Cartagena, otros acontecimientos secundarios empeoraron aún más el panorama que se cernía sobre su economía: el fin del comercio con Orán, tras la expulsión de su colonia judía en 1669; la decadencia mercantil de mediados del XVII en ciudades como Géno-

47 Gutierrez Nieto, J.I./CAStillo, A.: «El sistema fiscal de la monarquía de Felipe IV», en Historia de España, fundada por R. Menéndez Pidal, vol. XXVI, Madrid (1982), p. 290.

Hispania, LXV/2, núm. 220 (2005) 485-514 
va, Livorno, Marsella, etc., los principales valores del comercio cartagenero; la crisis de la Castilla interior que reducía los flujos mercantiles tradicionales (caso de la lana); la pequeña competencia en el Sureste de nuevos espacios litorales menos gravados, como Almería (en la exportación de lana), Garrucha (barrilla), Cope y Aguilas (pescado y barrilla), etc., acabaron confluyendo, y de alguna forma prepararon el estancamiento del modelo terciario cartagenero a mediados del siglo XVII.

Las consecuencias finales de este proceso pueden presuponerse fácilmente: empeoramiento de las ventajosas condiciones fiscales gozadas por los cartageneros desde antiguo, recorte progresivo de las exenciones tributarias de la ciudad, encarecimiento constante de los artículos objeto de comercio, aumento de las contribuciones soportadas por los mercaderes, reducción de los márgenes de ganancia que repercutían directamente sobre el dinero pagado a los campesinos (por su barrilla, sosa, esparto) y ganaderos (por la lana de sus rebaños), una contabilidad municipal embargada y arruinada, que imposibilitaba las inversiones en obras públicas (dejan de repararse los muelles) o la defensa de los privilegios fiscales de Cartagena, etc. En definitiva, una situación difícilmente sostenible, provocada por una desmesurada fiscalidad de guerra que provocó de forma directa la huida despavorida de muchos mercaderes cartageneros hacia otros paraísos fiscales (caso de Alicante y Cádiz) o a puertos y ciudades con mayor atractivo económico (Madrid, Sevilla, Málaga o los enclaves portuarios del Golfo de Cádiz).

Vemos en consecuencia que aunque la vitalidad económica del Sureste español se mantuvo a salvo (sobre todo en Alicante) en un panorama general de crisis, el puerto de Cartagena fue más sensible a los efectos múltiples de la recesión del Seiscientos, sobre todo agobiado por la asfixiante presión fiscal a la que fue sometido. Podemos hablar, por tanto, de estancamiento, pero no de crisis. Entre otras cosas porque pudo sobrevivir con ese modelo socioeconómico forjado a mediados del XVI, aunque en una situación menos expansiva. En este sentido Cartagena si tuvo su pequeña crisis o desaceleración del pulso económico, localizada en torno a las décadas centrales (1640-1670), en las cuales si podemos ponderar una limitada «crisis del siglo XVII». A partir de entonces - y hasta el primer tercio del XVIII- se producirá una readaptación de su modelo económico para no hacerlo tan dependiente de la vitalidad comercial generada por su puerto. Será un modelo de tipo mixto, articulado en torno a la expansión agraria de su campo y al mantenimiento de una actividad portuaria más modesta, ya que la primacía naval en el Sureste español se había decantado de forma clara y desde hacía tiempo hacia Alicante. 